\title{
Actualización:
}

\section{Estudios de laboratorio: primera entrega}

Laboratory tests: part one

Carina Auger* Fernando Mijalec ${ }^{\star *}$ Gabriel Ruiz ${ }^{\star \star}$

\begin{abstract}
Resumen
Los autores describen los fundamentos y la utilidad clínica de algunas pruebas de laboratorio: velocidad de sedimentación globular o eritrosedimentación, Dímero D, investigación de trombofilia, proteína C reactiva $(\mathrm{PCR})$ y hemograma.

Abstract

In this first article the authors describe the bases and clinical utility of some laboratory tests: glomerular sedimentation rate, D Dimer, trombophilia investigation, C protein levels and hemogram.
\end{abstract}

Palabras clave: pruebas de laboratorio, eritrosedimentación, dímero D, trombofilia, proteína C reactiva, hemograma. Key words: laboratory tests, glomerular sedimentation rate, D Dimer, trombophilia, C protein levels and hemogram.

Auger C, Mijalec F y Ruiz G. Estudios de laboratorio: primera entrega. Evid. actual. práct. ambul; 12(4):138-140, Oct-Dic.2009.

\section{Introducción}

Si bien el concepto de análisis o "chequeo" de rutina en personas asintomáticas está muy difundido entre las distintas especialidades médicas y en la población general, pocas de estas estrategias de rastreo tienen un fundamento científico que las avale.

Hay muchos motivos por los que estas prácticas se realizan a pesar de la falta de evidencia de beneficio. Entre otros podemos mencionar: 1) la desconfianza o incertidumbre por parte de los médicos o de los pacientes respecto del nivel de certeza que aportan las distintas maniobras de la clínica comprendidas en el interrogatorio y el examen físico, 2) la intención de pesquisar alguna enfermedad que se encuentra todavía en su período asintomático; 3) algún tipo de inercia del sistema (como siempre se hizo así, si dejo de hacerlo de ese modo le va a parecer al paciente o a su familia que no lo estamos cuidando con los estándares adecuados), por ejemplo en las evaluaciones prequirúrgicas; 4) por medicina "defensiva" y con el objetivo de prevenir eventuales problemas judiciales.

Sin embargo, está recomendado afirmarse primero en una buena historia clínica y un examen físico adecuado para que el rendimiento de los análisis sea optimizado y nos permita ser más precisos en la confirmación o en el descarte de algún eventual diagnóstico ${ }^{1}$.

Cuando no se ha cumplido con la caracterización inicial del paciente a través de un interrogatorio y examen físico apropiados, el resultado de los exámenes complementarios puede arrojar más confusión que claridad, lo que puede conducir a la generación de cascadas diagnósticas que podrían haberse evitado si se hubiera procedido con racionalidad desde el inicio del proceso diagnóstico.

Por lo tanto consideramos necesario hacer una revisión de los métodos diagnósticos de uso más generalizado, con el objetivo de optimizar su uso en forma racional y orientado a la condición clínica del paciente en cuestión.

En esta primera entrega de EVIDENCIA, describiremos los principales fundamentos y situaciones clínicas en las cuales algunas pruebas del laboratorio bioquímico o hematológico son de clara utilidad: la velocidad de sedimentación globular, la determinación del Dímero D, la investigación de la trombofilia, la determinación de los niveles de proteína $\mathrm{C}$ reactiva $(\mathrm{PCR}) ; \mathrm{y}$, por ultimo, el Hemograma.
Velocidad de sedimentación globular (VSG) o "eritrosedimentación"

Se trata de un estudio poco costoso, fácil de interpretar por el bioquímico, potencialmente sensible pero muy inespecífico ${ }^{2,3}$, ya que puede aumentar en presencia de condiciones clínicas potencialmente confundidoras como la anemia, o bien respecto de la edad, el sexo, el uso de tabaco u otras drogas.

Debe determinarse en sangre fresca y su valor normal varía entre 2 y $15 \mathrm{~mm} / \mathrm{hora}^{1,4,5}$.

No existe evidencia alguna que avale su pedido en pacientes asintomáticos, por lo que no debería ser incluida en pruebas de tamizaje poblacional ${ }^{2,6,7,8,9}$. En este sentido, un buen interrogatorio y examen físico orientan mucho mejor hacia la mayoría de los diagnósticos posibles. Por otro lado, ante individuos asintomáticos existen pruebas de mejores características operativas (especialmente especificidad) para implementar estrategias de rastreo de algunas entidades en particular, especialmente el cáncer oculto y en etapas en las que todavía sea curable $^{6}$. Las principales a mencionar son la prueba de sangre oculta en la materia fecal para el cáncer colorrectal, el Papanicolau para el cáncer de cérvix, la mamografia para el cáncer mamario. En el caso de que estemos ante un paciente con sospecha de cáncer avanzado, una cifra superior a 100 $\mathrm{mm} / \mathrm{h}$ es altamente sugestiva de metástasis.

Sin embargo existen algunas entidades nosológicas en las que la determinación de la VSG aporta una importante información que optimiza el proceso diagnóstico, como la sospecha de tiroiditis subaguda de Quervain', arteritis de la arteria temporal y polimialgia reumática (como criterio diagnostico), así como para monitorear su evolución ${ }^{10}$.

Si bien puede utilizarse para el seguimiento de pacientes con artritis reumatoidea y otros desordenes del tejido conjuntivo ${ }^{9}$, actualmente está discutida su utilidad en el seguimiento de pacientes con espondilitis anquilosante ${ }^{11}$.

Otra de las utilidades de la determinación de la VSG es el monitoreo de la respuesta al tratamiento de la enfermedad Hodgkin, 12

En cuanto a su capacidad para discriminar el dengue de otros síndromes febriles, esta ha sido reportada como baja, aún en las zonas endémicas ${ }^{13}$.

\section{Dimero D}

Ante la producción de una trombosis, inmediatamente se desencadena una respuesta fibrinolítica, en la que uno de los productos de degradación de la fibrina es el Dímero D. En este

* Médico Generalista. Caucete, San Juan

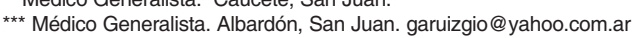


sentido podemos decir que la ausencia de Dímero $D$ es un indicador muy sensible que prácticamente descarta que se haya producido una trombosis ${ }^{14}$. Sin embargo, la presencia de Dímero D no es altamente específica de trombosis; en ese caso se debe realizar alguna prueba de referencia para confirmarla, como la ecografía doppler de miembros inferiore ${ }^{1,6,15,16,17}$.

Existen situaciones que conducen a la aparición de resultados falsamente positivos de Dímero D o dicho de otro modo, positividad de los dosajes de Dímero $D$ en ausencia de trombosis: embarazo, durante las primeras cuatro semanas posteriores a una cirugía, durante un trauma o una infección. Por lo tanto ante estas situaciones clínicas el dosaje de Dímero $D$ pierde valor.

Las indicaciones precisas para solicitar una determinación de Dímero $\mathrm{D}$ son la presencia o sospecha de coagulación intravascular diseminada (CID), de trombosis venosa profunda con clínica franca y la evaluación del curso de un tratamiento antitrombótico ${ }^{1,6,14,15,17 .}$

Cuando se toma como punto de corte una concentración de $500 \mathrm{ng} / \mathrm{mL}$ de Dímero D medido mediante ELISA, esta prueba tiene una sensibilidad de $96 \%$ y según la probabilidad previa, un valor predictivo negativo (VPN) que puede ser superior a $99 \%$ para el diagnóstico de trombo embolismo pulmonar

\section{Trombofilia}

Los trastornos de la coagulación son entidades raras, por lo que no está indicado realizar un rastreo poblacional. La pesquisa de casos será necesaria en situaciones puntuales: pacientes con historia familiar de trastornos de coagulación ( $p$. ej. alteraciones del factor II); pacientes jóvenes con trombosis; mujeres con antecedentes de abortos recurrentes y, eventualmente, en algunos pacientes bajo tratamiento con anticoagulantes'.

Ante este tipo de situación clínica está recomendado solicitar determinaciones de Proteína C, Proteína S, Antitrombina, Factor V Leiden y Anticoagulantes Lúpicos ${ }^{1,18,19}$.

Cabe resaltar que no existe evidencia que avale actualmente la investigación rutinaria de trombofilia durante el embarazo, antes de la prescripción de preparaciones orales de estrógenos, ni previamente a la realización de una cirugía ortopédica importante ${ }^{20}$.

Sin embargo, podría considerarse la pesquisa de casos en pacientes embarazadas con historia personal o familiar de trombosis ${ }^{19}$.

\section{Proteína C Reactiva (PCR)}

La proteína $C$ reactiva $(\mathrm{PCR})$ es una proteína producida por el hígado cuyos niveles no se detectan normalmente, pero se elevan en presencia de fenómenos inflamatorios. Normalmente, la PCR no supera los $0,5 \mathrm{mg} / \mathrm{dL}^{21,22}$ y su presencia es tan inespecífica como la elevación de la VSG. Por ejemplo, durante la segunda mitad del embarazo o durante el uso de anticonceptivos orales, pueden elevarse los niveles de PCR sin que esto tenga significado patológico.

La determinación de PCR tiene un alto valor predictivo negativo para descartar infecciones invasivas en pacientes con estados febriles, siempre que la determinación se realice luego de 12 horas de la evolución de dicho estado febril23.

Valores de PCR superiores a $10 \mathrm{mg} / \mathrm{dL}$ hacen pensar en infecciones bacterianas de diferente localización (artritis infecciosa, meningitis bacteriana, neumonía bacteriana, pielonefritis y celulitis infecciosa); mientras que valores inferiores a $10 \mathrm{mg} / \mathrm{dL}$ pueden aparecer en pacientes con enfermedades reumáticas como lupus y artritis reumatoidea.

Por último, valores de PCR inferiores a $1 \mathrm{mg} / \mathrm{dL}$ pueden verse en pacientes con asma, accidente cerebro-vascular, cistitis, meningitis aséptica, otitis media, hepatitis viral, deshidratación, pancreatitis crónica, cirrosis y ascitis no infecciosa ${ }^{22}$.

Para resumir, podemos decir que la PCR es un marcador inespecífico de inflamación que puede tener valor orientativo pero que no "hace diagnóstico" de ninguna de las entidades clínicas mencionadas previamente ${ }^{21}$.

Por último, en los últimos años ha ganado terreno una técnica de medición de la PCR (la PCR ultrasensible) que serviría para afinar la precisión de la estimación del riesgo de desarrollar cardiopatía ${ }^{24}$.

\section{Hemograma}

Se trata de un estudio que permite la evaluación de cambios cualitativos y cuantitativos en los hematíes, las plaquetas y los leucocitos.

\section{Cambios relacionados con los leucocitos}

La serie blanca incluye a los leucocitos polinucleares o granulocitos (neutrófilos, basófilos y eosinófilos) y a los leucocitos mononucleares (linfocitos y monocitos). Se dice que un pacientes presenta leucocitosis cuando su serie blanca está por encima de $11 \times 10^{9} /$ leucocitos $^{12,24}$, denominándose reacción leucemoide al estado en que los valores superan 30 a 50 x $10^{9} / L^{12,24,25}$

En el hemograma es muy importante el estudio cualitativo del frotis de sangre fresca para evaluar el grado de granulación y segmentación de los neutrófilos y/o la presencia de blastos ${ }^{27}$. Por lo tanto, ante cualquier alteración, del hemograma hay que ver si hay células maduras o existe "mielemia", o si solo hay un aumento de la serie blanca y/o de los demás componentes (plaquetas, eritoblastos) ${ }^{12}$

Ante la presencia de leucocitosis, siempre es necesario confirmarla en las dos a cuatro semanas posteriores ${ }^{27}$.

La neutrofilia' $^{12}(8000$ a $10000 / \mathrm{mL})$ suele deberse a situaciones fisiológicas como el ejercicio, el estrés, o el embarazo. Sin embargo, más raramente puede ser consecutiva a procesos patológicos que producen reacciones "inflamatorias" como las infecciones bacterianas o virales; algunos tumores (el cáncer gástrico, de mama o broncogénico) situaciones que provocan inflamación y necrosis (como los infartos agudos de miocardio y las quemaduras) o fármacos ${ }^{27}$ (corticoides, digital).

Por otro lado, una de las causas más comunes de linfocitosis (mayor a $5000 / \mathrm{mL}$ ) ${ }^{24-26-27}$ es la mononucleosis infecciosa, que suele cursar con valores que superan los $15000 / \mathrm{mL})^{12}$, mientras que la eosinofilia (valores por encima de $500 / \mathrm{mL}$ ) suele ser consecutiva a procesos asmáticos/alérgicos y/o a infecciones por parásitos (helmintos) ${ }^{12,26}$. Las monocitosis (más de $900 / \mathrm{mL}$ ) es una alteración muy rara que puede verse en el contexto de algunas infecciones crónicas.

Las causas más comunes de neutropenia (menos de 4300/mL) son la inducción por fármacos o luego de alguna infección ${ }^{24}$, pudiendo también aparecer en pacientes con enfermedades del colágeno, infecciones crónicas, o en el síndrome de neutropenia crónica idiopatica. La linfopenia (valores menores a $1500 / \mathrm{mL})^{12}$ puede verse en pacientes con insuficiencia cardíaca congestiva, en etapas iniciales de la enfermedad de Hodgkin; mientras que la eosinopenia y basopenia, en enfermedad de Cushing y enfermedades alérgicas (especialmente la basopenia). 


\section{Cambios relacionados con las plaquetas}

El recuento de plaquetas se utiliza para conocer como funciona la médula ósea y ofrece datos para algunas enfermedades que cursan con trombocitopenia o trombocitosis.

Los valores normales son variables según los autores ${ }^{12-26-27}$ y a modo estimativo oscilan entre 150000 y $450000 / \mathrm{mL}$. Valores disminuidos de plaquetas pueden verse en el contexto de infecciones agudas, durante el shock o en pacientes con púrpuras. Entre las causas más comunes de trombocitopenia (menos de $150000 / \mathrm{mL}$ ) se encuentran el hiperesplenismo y el aumento de su destrucción por procesos inmunes o no inmunes; mientras que su aumento en el número puede ser debido a procesos hemoproliferativos. Sin embargo, es importante tener presente que algunos fármacos como la indometacina, la heparina y la penicilina, pueden alterar su recuento. No se recomienda efectuar rastreo de alteraciones cuantitativas de las plaquetas ${ }^{12}$.

\section{Hematocrito}

El hematocrito, cuyos valores normales oscilan entre 37 y 47 en mujeres y entre 42 y 52 en varones ${ }^{24,27,28}$ expresa tanto la concentración de los eritrocitos como su volumen, valorado como volumen corpuscular medio (VCM).

Su medición sirve para valorar anemia, policitemia y la respuesta al tratamiento de estas, el grado de una deshidratación, la decisión de efectuar una transfusión de sangre en pacientes con anemias graves sintomáticas así como la efectividad de dichas transfusiones ${ }^{29}$.

La sistemática para caracterizar una anemia con el objetivo de arribar a su causa excede los alcances de este artículo y deberá consultarse en textos especializados.

\section{Referencias}

1. Trinick T y col. Guidelines on the use of the laboratory guidelines \& audit guidelines \& audit implementation network (internet) U.K march 2008. Avaliable at www.gain-ni.org

2. Guidelines and Protocols Advisory Committee, British Columbia Medical Association and Medical Services Commission. Erythrocyte Sedimentation Rate Effective Date: December 15, 2006.

3. Sales M y col. Revisión de la evidencia en el tratamiento de la enfermedad pélvica inflamatoria Ginecología y Obstetricia Clínica 2005;6(3):134-138

4. Malcolm L y col. Clinical Utility of the Erythrocyte Sedimentation Rate Cancer Agency, Kelowna, British Columbia, Canada

5. Saadeh C. The erythrocyte sedimentation rate: old and new clinical applications. South Med J 1998; 91(3): 220-5 (MEDLINE is the source for the citation and abstract of this record) Department of Internal Medicine, Texas Tech University Health Sciences Center, USA.

6. Ebell M y col.POEMs and Tips from Other Journals When Normal D-Dimer Equals Low DVT Risk American Family Physician. April 21, 2003.

7. The Ontario Association of Medical Laboratories. Guideline for the Ordering of Erythrocyte Sedimentation Rate MARCH 2001

8. Villarrubia J. ¿Sigue siendo útil la técnica de VSG? Hematologica Vol.88 Núm. Supl.6 ISSN:1138-0381

9. Amjad Hameed M y col. Physiological basis and clinical utility of erythrocyte sedimentation rate. Pak J Med Sci April-June 2006 vol. 22 no. 2 Pág $214-218$. continuing medical education. www.pjms.com.pk

10. Aguirre Errasti C y col. Polimialgia Reumática. Enfermedades Sistemáticas en Farreras Rozman Medicina Interna [CD-ROM] 14 ed. Harcourt-Brace. Sección 7 Parte II Capitulo 152. 11. Spoorenberg A y col. Journal of Rheumatology Omeract IV Conference n 4, Cancun, Mexique (16/04/1998) 1999, vol. 26, no 4, pp. $945-1006$ (5 ref.) pp. $980-984$ journal of rheumatology publishing.

12. Cazap N y col. Alteraciones comunes de los parámetros del laboratorio en Rubinstein A. Terrasa S. Medicina Familiar y práctica Ambulatoria $2^{\circ}$ ed. Bs. As. Panamericana 2006 p. 881-887.

13. Uygur A y col. Erythrocyte sedimentation rate and c-reactive protein: are they still worthwhile? türk aile hek derg 2007; 11(4): 154-162

14. Arbelbide J. Dimero-D cuantitativo para descartar trombosis venosa profunda. EVIDENCIA Actualización en la Práctica Ambulatoria (internet) 2003 sep; vol. 6 no 5 : 144 disponible en: www.foroaps.org/hitalba-pagina-articulo.php?cod_producto=1234\&vol=6\&nr_bi=5\&ano=2003

15. Keeling $\mathrm{D}$ y col. The diagnosis of deep vein thrombosis in symptomatic outpatients and the potential for clinical assessment and D-dimer assays to reduce the need for diagnostic imaging. British Journal of Haematology, 124, 15-25

16. Gámez B y col. Valor del dímero-D para el diagnóstico de tromboembolismo pulmonar en el servicio de urgencias, emergencias 2000;12:6-11 disponible en www.semes.org/revista/vol12_1/6-11.pdf

17. Stein $\mathrm{P}$ y col. Dimer for the exclusion of acute venous thrombosis and pulmonary embolism: a systematic review. Ann Intern Med. 2004 Apr;140 (8):589-602.

18. Mainwaring C. et al. Audit of coagulation screen requests from patients admitted to the Medical assessment Unit The Royal College of Pathologists Pathology Department of haematology North Hampshire Hospital 2007 disponible en www.rcpath.org/.../AuditCoagualtionScreenRequestsPatientsAdmittedMAU_WEB.pdf -

19. Kim Graham. Trombosis venosa profunda: The Royal College of Path Evidence Summary. 2007 disponible en: www.rcpath.org

20. Chee Y. y col. Guideline on the assessment of bleeding risk prior to surgery or invasive procedures. London (UK): British Committee for Standards in Haematology; 2007. $\mathrm{p} \mathrm{25}$

21. Castellote Varona F. Velocidad de sedimentacion "extrema" vs. proteina C reactiva. Unidad Geriátrica. Hospital Universitario Virgen de la Arrixaca. Murcia. An Med Interna. (Madrid) 2008 May; 25(5):250-1 Print Version ISSN 0212-7199 disponible en www.scielo.isciii.es/scielo.php?script=sci_arttext\&pid=S0212-71992008000500018\&lng=en\&nrm=iso

22. Freire González M. Pruebas reumáticas Guías Clínicas fisterra. 2007; 7 (2). 23/01/2007. disponible en: www.fisterra.com

23. Caflisch M. "La Proteína C Reactiva en los Estados Febriles sin Foco de los Niños Menores de 24 Meses." Médecine et Hygiène 58: 366-370, 2000 traducido por Sociedad Iberoamericana de Información Científica (SIIC) 2002

24. Augustovski F y col. Proteína C Reactiva como marcador pronóstico en enfermedad cardiovascular. Evidencia Actualización en la Práctica Ambulatoria- Vol. 10 n 5: Sep-Oct 2007. Instituto de Efectividad Clínica y Sanitaria. Documentos de Evaluación de Tecnologías Sanitarias. Buenos Aires, Argentina. Informe de respuesta rápida n 108. Julio de 2007. Última Actualización: 07/2007.

25. Ramos Gutiérrez I y col. Recomendaciones prácticas para el médico de Familia Alteraciones analíticas. Alteraciones de la serie blanca: leucocitos. Sociedad Madrileña de Medicina de Familia y Comunitaria. Disponible en: www.somamfyc

26. Maldonado Eloy-García J y col. Enfermedades del sistema leucocitario trastornos cuantitativos en Farreras-Rozman Medicina Interna, 13를 ed. Harcourt-Brace pág.1672-1679

27. Domingo Claros A Problemas hematológicos en Zurro Martín Cano Pérez J. Atención Primaria. Conceptos, organización y práctica clínica. $4^{a}$ ed [CD-ROM] España Harcourt Brace. 1999.

28. Pérez Lorenzo N. Guías Clínicas 2005; 5 (3). Disponible en: Fisterra.com

29. Junca J. Un Algoritmo diagnostico para la ferropenia. Med Clin (Barc) 2001; 116: 146-149

30. Folsom A y col. An assessment of incremental coronary risk prediction using C-reactive protein and other novel risk markers: The Atherosclerosis Risk in Communities Study. Arch Intern Med 2006;166:1368-73. avaliable: www.turner-white.com

31. Romera A y col. Diagnóstico en urgencias de la trombosis venosa de miembros inferiores: valor de los criterios clínicos unidos al dímero-d. Angiología, ISSN 0003-3170, Vol. 57, № 3,2005 , p. 219-224 avaliable in: www.dialnet.unirioja.es/servlet/oaiart?codigo=1203099 